\title{
HIV na terceira idade: repercussões nos domínios da vida e funcionamento familiar*
}

HIV in the elderly: repercussions in the domains of life and family functioning

\author{
Aline Oliveira Silva** \\ Maria das Dôres Saraiva de Loreto*** \\ Simone Caldas Tavares Mafra****
}

\begin{abstract}
Resumo - O presente estudo teve como objetivo analisar os fatores intervenientes na aquisição do HIV, além de examinar as repercussões do HIV/Aids sobre os domínios da vida do idoso e no funcionamento familiar. Para tanto, foram realizadas entrevistas aos idosos com HIV/ Aids, que realizam tratamento no SAE/JF. Os resultados evidenciaram que a forma predominante de contágio era a sexual. Além disso, para a maioria dos idosos não ocorreram mudanças significativas em seus domínios da vida após a descoberta da doença. Já no que se refere ao funcionamento familiar, destacaram-se aqueles que contaram para a família e se sentiram acolhidos, seguidos daqueles que mantiveram sigilo sobre a doença. Conclui-se que o apoio da família ao idoso é de extrema importância no processo de adaptação à sua nova condição; no entanto, a vergonha e o medo do julgamento são fatores que contribuem para que os idosos mantenham em segredo a soropositividade, visando manter a estrutura das redes sociais existentes.
\end{abstract}

Palavras Chave: HIV; idosos; domínios da vida; funcionamento familiar.

\begin{abstract}
The objective of this study was to analyze the factors involved in HIV acquisition and to examine the impact of HIV/AIDS on the domains of family functioning and the elderly. For that, interviews were conducted with elderly people living with HIV/AIDS who undergo treatment in the Specialized Attention Serviceof thecity of Juiz de Fora, Minas Gerais. Results showed the predominant form of contagion is sexual. In addition,
\end{abstract}

\footnotetext{
* Este artigo foi desenvolvido a partir da dissertação de mestrado intitulada As representações da aids para a terceira idade, sob uma perspectiva de gênero: significados e repercussões nos domínios da vida do idoso e funcionamento familiar, que contou com o apoio da CAPES.

** Doutoranda do Programa de Pós-Graduação em Economia Doméstica da Universidade Federal de Viçosa, do Estado de Minas Gerais. Correspondência: Rua Áureo da Silva Lisboa, n 171 - Centro - Paula Cândido - Minas Gerais. CEP: 36544-000. Email: <aline.o.silva@ufv.br>.

*** Docente do Departamento de Economia Doméstica da Universidade Federal de Viçosa, do Estado de Minas Gerais. Correspondência: Universidade Federal de Viçosa/ DED, Campus Viçosa, Avenida Peter Henry Rolfs, s/ n, Viçosa - Minas Gerais. CEP: 36570-900. Email: <mdora@ufv.br>.

**** Docente do Departamento de Economia Doméstica da Universidade Federal de Viçosa, do Estado de Minas Gerais. Correspondência: Universidade Federal de Viçosa/ DED, Campus Viçosa, Avenida Peter Henry Rolfs, s/ n, Viçosa - Minas Gerais. CEP: 36570-900. Email: <sctmafra@ufv.br>.
} 
for the majority of the elderly there were no significant changes in their domains of life after discovering the disease. Regarding the family functioning, those who informed their families and felt welcomed stood out, followed by those who remained secretive about the disease. It was concluded that family support for the elderly is extremely important in the process of adapting to their new condition; however, shame and fear of judgment are factors that contribute to the elderly keeping the seropositivity in secret, in order to maintain the structure of existing social networks.

Keywords: HIV; elderly; domains of life; family functioning.

\section{Introdução}

No início de 1980, surgiu a epidemia da aids trazendo consigo uma série de dúvidas sobre a doença, além de estigma e discriminação para com as pessoas portadoras do vírus. Esse estigma está relacionado ao fato de os primeiros casos da doença terem sido registrados entre os homossexuais e usuários de drogas, sendo que esses grupos, até então, já eram excluídos da sociedade (BERNARDI, 2005).

No entanto, conforme apontam Santos e Assis (2011), a epidemia da aids vem sofrendo diversas modificações em seu perfil ao longo dos anos, dentre as quais destacam-se os fenômenos de feminilização, heterossexualização, juventudilização, pauperização e envelhecimento. O aumento do número de casos de HIV entre os idosos tem sido associado ao enveIhecimento da população brasileira, ao aumento da sobrevida das pessoas portadoras do HIV/Aids e ao acesso a medicamentos para distúrbios eréteis, fator que tem prolongado a atividade sexual de idosos, em associação com a desmistificação do sexo na terceira idade.

Muitas são as causas atribuídas ao aumento dos índices de contaminação e de idosos vivendo com o HIV/Aids, dentre eles: mudanças socioculturais, sobretudo na sexualidade; resistência por parte dos idosos em utilizar camisinha; inovações na área da saúde; acesso à terapia antirretroviral e inovações na área medicamentosa (SERRA et al., 2013).

Para Barros, Guimarães e Borges (2012), a partir do reconhecimento mundial pelas autoridades sanitárias da ocorrência e gravidade dos agravos produzidos pelo HIV/Aids, a enfermagem, tanto no Brasil, quanto nos demais países, passou a exercer seu papel profissional e social, seja na área preventiva, seja na cuidativa.

Schröder (2012) destaca que, graças aos avanços no tratamento da aids, nota-se uma melhora na sobrevida da população, mesmo após a manifestação dos sintomas. O tratamento com antirretrovirais possibilita que as pessoas portadoras do HIV vivam por mais tempo e com mais qualidade. Desse modo, percebe-se uma nova categoria relacionada às pessoas com aids na terceira idade, pois existem aquelas que contraíram o vírus após os 60 anos de idade, mas também existem aqueles que já envelheceram 


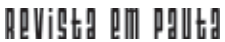

\} HIV NA TERCEIRA IDADE - SILVA, A. O.; LORETO, M. D. S.; MAFRA, S. C. T. \}

DOI 10.12957/REP.2017.30380

com o HIV, uma vez que os sintomas podem levar anos para se manifestar. No entanto, não importa com que idade se adquiriu o HIV/Aids, é preciso tratar sobre esse assunto com as pessoas idosas, uma vez que este tema traz desafios, medos, contradições e preconceitos.

No aspecto social, o idoso convive com o estigma associado ao estar com aids, ao medo dos familiares e da comunidade, à diminuição dos recursos financeiros, além das questões ligadas à qualidade de vida (SERRA et al., 2013).

Nesse sentido, pressupõe-se que a aids afeta tanto os domínios da vida dos idosos quanto o funcionamento familiar. Segundo Addams (2005), os principais domínios ou componentes da vida de um indivíduo envolvem as seguintes esferas: trabalho, vida familiar, saúde, religião, amizades, situação financeira, tempo livre e vizinhança. Esses domínios podem ser percebidos pelos indivíduos de forma diferenciada, em função da importância dos mesmos na vida das pessoas, ambiente vivenciado e fases do ciclo de vida. Por outro lado, o funcionamento familiar diz respeito à forma de organização e envolvimento familiar, apoio e proteção, além de flexibilidade frente às situações adversas e imprevistas. Como destaca Bray (1995), o funcionamento familiar está associado à composição familiar, aos processos familiares (fatores comportamentais e interacionais), à organização familiar (regras e normas), além da afetividade, em termos das relações de afeto ou apoio.

Entende-se que, diante do impacto do diagnóstico, deve surgir uma explosão de sentimentos vindos da dúvida sobre contar ou não para os amigos e familiares, ou até mesmo para outras pessoas próximas. Esse sentimento acaba por afetar os processos de comunicação e relacionamento com as pessoas, o que pode levar o paciente a se isolar, enfrentando sozinho sua nova condição. Apesar disso, como destacam Diniz, Saldanha e Araújo (2010), é de grande importância o suporte familiar ao paciente no processo de adaptação à nova realidade.

Assim, o presente artigo objetivou analisar os fatores intervenientes para a aquisição do HIV, além de examinar as repercussões da doença sobre os domínios da vida do idoso e sobre o funcionamento familiar.

\section{Revisão de literatura}

\subsection{Consequências e implicações do HIV/Aids na terceira idade}

O estigma e o preconceito relacionados ao HIV ocasionam diversas consequências negativas no que se refere à luta contra a aids, tanto no que tange às pessoas que vivem com o vírus, quanto no que concerne às estratégias de prevenção (JARDIM, 2012). Para Almeida e Labronici (2007, p.265), 
em função das representações, advindas do preconceito e da ignorância, as pessoas com o HIV e a aids vivenciam emoções singulares, permeadas de sofrimento dentro de um contexto repleto de significados, entre os quais, o medo do abandono, de ser julgado e de revelar sua identidade social, a culpa pelo adoecimento, a impotência, a fuga, a clandestinidade, a omissão, a exclusão e o suicídio, originados e construídos pelo real convívio com o social que reforça os hábitos e expectativas e que estão profundamente enraizados numa sociedade preconceituosa.

A descoberta e revelação da soropositividade é um evento crucial na vida tanto do portador quanto da família e dos amigos. A percepção negativa, a discriminação e a falta de conhecimento difundem o sofrimento, o medo do abandono e do julgamento. A quebra do padrão de vida, a impotência diante da nova realidade e o consumo exagerado de bebidas alcoólicas são alguns dos aspectos relacionados a uma doença estigmatizada (ALMEIDA; LABRONICI, 2007).

Especificamente nos idosos, a ampliação no número de infectados com o HIV pode estar relacionada a uma falha em relação às tentativas de prevenção para esse grupo, pois, muitas vezes, as campanhas voltam sua atenção para a população mais jovem. Outro fator que contribui para o aumento dos casos de aids em idosos é a sexualidade estereotipada, que é culturalmente produzida na sociedade. Os estereótipos de que as pessoas idosas não têm interesse por sexo ou que são incapazes de sentir algum estímulo sexual ainda são amplamente difundidos e, juntamente a isso, a prática sexual sem proteção contribui para que esse diagnóstico aumente cada vez mais (CELEDÔNIO; ANDRADE, 2014).

Jardim (2012) relata que o uso do preservativo também sofre influências da existência de tabus, uma vez que muitas pessoas, ao não se identificarem como imorais ou promíscuas, não se veem em situação de vulnerabilidade e não se protegem. Os idosos muitas vezes não se percebem vulneráveis ao HIV, e até mesmo os profissionais de saúde não têm considerado o público idoso em situação de vulnerabilidade. Para Araújo et al. (2007), pensar o envelhecimento sem sexualidade acarreta graves consequências, sobretudo para a prevenção, pois esta só vai ocorrer caso os familiares e profissionais de saúde estejam atentos para discutir abertamente sobre o assunto.

Outro ponto a ser destacado diz respeito ao comportamento diferenciado dos idosos em face do contágio, sendo mais comum entre homens e com maior nível socioeconômico (GOMES; SILVA, 2008). Além disso, como destaca Feijó (2006), é comum, nessa situação, a existência de preconceitos, vergonha, depressão e outros aspectos que diminuem o contato e a qualidade do relacionamento com as redes de convivência.

Como relatam Saldanha, Felix e Araújo (2008), além de toda a carga sociomoral que carrega um soropositivo, na velhice algumas construções sociais contribuem para o aumento das dificuldades enfrentadas 


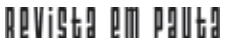

\} HIV NA TERCEIRA IDADE - SILVA, A. O.; LORETO, M. D. S.; MAFRA, S. C. T. \}

DOI 10.12957/REP.2017.30380

pelo idoso. O medo da dupla rejeição social leva muitos idosos a procurarem mecanismos de aceitação social, como, por exemplo, alegarem que a forma de contágio foi através de transfusão sanguínea, negando assim o comportamento sexual vulnerável.

Em estudo realizado por Andrade, Silva e Santos (2010) com 75 idosos portadores do HIV, estes descreveram que a descoberta da doença acarretou vivências de estigma e discriminação. Além disso, foram apontadas pelos idosos as limitações físicas, a necessidade de acompanhamento clínico ou o uso contínuo dos medicamentos e suas eventuais consequências. Foram citados também sentimentos de incredulidade, isolamento e receio de discriminação, tanto da família quanto do serviço de saúde. Ou seja, a aids tem implicações não somente sobre os domínios da vida dos idosos, mas também no funcionamento de suas famílias, o que leva à busca de apoio ou conforto emocional.

Os referidos autores comentam que a busca por meios de ajuda ou apoio é considerada uma reação natural do ser humano que está passando por uma situação complicada sob forte estresse, na procura por um conforto emocional. Isto é, há uma busca por redes de apoio, tanto formais quanto informais, visando ao enfrentamento dos problemas e à saída da crise (ANDRADE; SILVA; SANTOS, 2010).

Na visão dos autores, as redes de suporte ou apoio social são conjuntos hierarquizados de pessoas que mantêm entre si laços típicos de relações em que se dá e recebe apoio, e nas quais costuma-se fornecer ajuda material, serviços e informações; permitir às pessoas crerem que são cuidadas, amadas e valorizadas em momentos de alguma necessidade; dar garantia de que pertencem a uma rede de relações comuns e mútuas; entre outros. O suporte social se torna importante na medida em que corresponde às necessidades experienciadas pelo próprio idoso. Dentro dessa perspectiva, o suporte social inclui uma rede ampla de suporte emocional, informacional e instrumental.

Assim, a gerontologia classifica os sistemas de apoio em formais e informais, sendo os "formais os serviços de atendimento ao idoso, que incluem hospital, atendimento domiciliar, instituições de abrigamento, programas de capacitação de recursos humanos"; já os "informais são as redes de relacionamento entre os membros da família, amigos e vizinhos e, dessa forma, deverão constituir-se em redes de ações de referência, informação, orientação e encaminhamento, e outra de inclusão e proteção social" (ANDRADE; SILVA; SANTOS, 2010, p.6).

Pode-se dizer que, para os soropositivos, a família é a principal fonte de apoio, sendo que o afastamento desse contato pode gerar grandes prejuízos. Em alguns casos, como destacam Carvalho e Paes (2011), o que acontece é que o medo do preconceito e do isolamento fazem com que o portador do HIV esconda dos seus familiares o diagnóstico. Isso torna o enfrentamento da doença um processo solitário, pois muitas vezes ele acredita 
que se revelar seu diagnóstico será rejeitado pela família, abandonado e discriminado.

\section{Metodologia}

Visando atender ao objetivo proposto, fez-se uso de um modelo de pesquisa de natureza qualitativa, que, segundo Paulilo (1999), trabalha com valores, crenças, hábitos, atitudes, representações e opiniões, buscando adequação e aprofundamento sobre a complexidade dos fatos e processos particulares a indivíduos e grupos. Minayo (2012) complementa dizendo se tratar daquelas metodologias capazes de incorporar a questão do significado e da intencionalidade, como inerentes aos atos, às relações e às estruturas sociais. Essas últimas são tomadas tanto no seu advento quanto na sua transformação, como construções humanas significativas.

Assim, pretendeu-se, por meio de um estudo de casos múltiplos, integrar métodos de pesquisa qualitativa, pois esse tipo de pesquisa responde a questões muito particulares da realidade social. Conforme Minayo (2012), na pesquisa em Ciências Sociais trabalha-se com o universo dos significados, dos motivos, das aspirações, das crenças, dos valores e das atitudes, considerando que o ser humano se distingue não só por agir, mas por pensar sobre o que faz e por interpretar suas ações dentro e a partir da realidade vivida e compartilhada.

O presente estudo foi realizado no município de Juiz de Fora (MG), localizado a sudeste de Belo Horizonte, lugar que se destaca, em Minas Gerais, no ranking de desenvolvimento humano da Organização das Nações Unidas (ONU), conforme Guercio (2004).

A unidade empírica de análise compreendeu o Serviço de Assistência Especializada (SAE), que foi implantado em Juiz de Fora em 28 de setembro de 1996, com o objetivo de atender tanto aos pacientes do município quanto da Zona da Mata (GUERCIO, 2004).

A população estudada compreendeu homens e mulheres idosos (60 anos ou mais) com HIV/Aids, que fizeram consultas nos seis meses anteriores a junho de 2015 no SAE, em Juiz de Fora/MG, e cujos prontuários foram abertos no período de 2007 a 2013, de modo que o paciente tivesse pelo menos dois anos de diagnóstico. Assim, para um total de 85 idosos, 64 foram considerados elegíveis. Destes, 33 eram do sexo masculino e 31 do sexo feminino.

Em função desse universo populacional foi delimitada a amostra baseando-se no cálculo amostral para população finita, que, de acordo com Triola (2013), segue a seguinte fórmula:

$$
n=\frac{\mathrm{N} \sigma^{2}(\mathrm{Z} \alpha / 2)^{2}}{(\mathrm{~N}-1) \mathrm{E}^{2}+\sigma^{2}(\mathrm{Z} \alpha / 2)^{2}}
$$




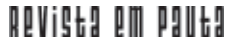

\} HIV NA TERCEIRA IDADE - SILVA, A. O.; LORETO, M. D. S.; MAFRA, S. C. T. \}

DOI $10.12957 /$ REP.2017.30380

Onde,

$\mathrm{n}=$ Número de indivíduos na amostra;

$\mathrm{N}$ = População de idosos assíduos que abriram prontuário no SAE de 2007 a 2013;

Zá/2 = Valor crítico que corresponde ao grau de confiança desejado, aqui estabelecido em $90 \%$, sendo, portanto, equivalente a 1,65;

$\mathrm{o}^{2}=\mathrm{p} \times \mathrm{q}$;

$\mathrm{p}=$ Proporção populacional de indivíduos que pertencem à categoria a ser estudada;

$q(1-p)=$ Proporção populacional de indivíduos que não pertencem à categoria a ser estudada, igual a 0,5 ;

$\mathrm{E}=$ Margem de erro ou erro máximo de estimativa, aqui estabelecida em 0,1 ;

Assim, o tamanho da amostra de idosos foi:

$$
n=\frac{64 \times 0,5 \times 0,5 \times(1,65)^{2}}{63 \times(0,1)^{2}+0,5 \times 0,5 \times(1,65)^{2}}=n=\frac{43,56}{1,32}=33 \text { idosos com aids }
$$

Dessa forma, a amostra foi de 33 idosos, sendo $52 \%$ do sexo masculino $(n=17)$ e $48 \%$ do sexo feminino $(n=16)$.

\subsection{Procedimentos de coleta e análise de dados}

A coleta de dados é a forma como se obtêm os dados necessários para responder ao problema da pesquisa (VERGARA, 2005). Para este estudo, a técnica de coleta de dados utilizada foi a entrevista semiestruturada, realizada com 33 idosos no período de junho a julho de 2015.

Para tanto, foi elaborado um roteiro com o propósito de orientar a coleta dos depoimentos. Pretendeu-se indagar os entrevistados sobre: como se deu a descoberta da doença; com qual idade descobriu a doença; como se deu o contágio pelo HIV/Aids (vulnerabilidades/riscos sociais); se já se sentiu discriminado e como reagiu; como tem sido o tratamento; quais foram as principais redes de apoio que o idoso recorreu após a descoberta da doença; e quais foram as mudanças que a doença causou nos seguintes domínios da vida: trabalho, vida familiar, saúde, religião, amizades, situação financeira, tempo livre e vizinhança, bem como sobre o funcionamento familiar, em termos de: composição da família, normas e regras, formas de interação, comportamentos dos membros, relações de afeto e apoio, conflitos, comunicação e envolvimento familiar no enfrentamento da doença.

A intenção foi seguir um roteiro prévio, embora tenha havido liberdade para que os entrevistados pudessem fazer associações concernentes à sua história de vida que considerassem relevantes. 
As entrevistas foram realizadas no $\mathrm{SAE}$, em uma sala disponibilizada pelo coordenador, de modo a possibilitar que os participantes fossem abordados e convidados a participar da pesquisa enquanto aguardavam o atendimento médico ou ao saírem da consulta.

Vale ressaltar que o projeto foi submetido ao Comitê de Ética em Pesquisa com Seres Humanos da Universidade Federal de Viçosa (UFV), sendo aprovado sob o registro Caae 45259815.4.0000.5153. Além disso, todo o processo de coleta de dados foi viabilizado mediante assinatura do Termo de Consentimento Livre e Esclarecido (TCLE) pelos participantes da pesquisa.

Após a coleta dos dados, estes foram analisados a partir da técnica de análise de conteúdo proposta por Bardin (2011). Conforme Caregnato e Mutti (2006), a análise de conteúdo é uma técnica de pesquisa que trabalha com a palavra, permitindo produzir inferências do conteúdo da comunicação de um texto replicável ao seu contexto social. Assim, é um meio de expressão do sujeito, no qual o pesquisador procura categorizar as unidades de texto (palavras ou frases) que se repetem, buscando uma expressão que as represente.

\section{Resultados e discussões}

\subsection{Fatores intervenientes na aquisição da doença pelos idosos}

No que se refere aos fatores intervenientes na aquisição da doença, levou-se em consideração a forma de contágio, o modo como descobriu a doença, o motivo do aumento de casos de HIV/Aids em idosos, o preconceito contra a doença, a forma como tem sido o tratamento, as estratégias adotadas para conviver com a doença e as políticas de controle e prevenção.

Ao serem questionados sobre como se deu o contágio, 31 idosos responderam que foi de forma sexual, sendo que a maioria não sabia quem era a pessoa que havia Ihe contaminado. Uma entrevistada, contudo, sofreu abuso sexual por ser moradora de rua. Além disso, destacam-se aqueles que adquiriram a doença a partir da relação sexual com os próprios companheiros, além de duas mulheres que afirmaram terem adquirido a doença a partir da transfusão sanguínea.

A seguir, apresentamos algumas falas dos entrevistados sobre a forma como se deu o contágio.

Tenho a dúvida se foi sexual, pelo meu marido, ou se foi através de uma transfusão que eu tinha feito há um tempo atrás. Eu tenho essa dúvida até hoje, mas eu fui a São Paulo porque eu tive tuberculose, aí eu fui a São Paulo para saber se naquela época achava alguma coisa da aids, e o médico que me tratou afirma que, naquela época, não tinha nada. (Entrevistada n. 22).

Eu não sei te explicar, mas é relação sexual aids em idosos: vivências dos doentes. (Entrevistada n. 27). 
Transfusão de sangue quando ganhei meu filho e tive uma hemorragia. (Entrevistada n. 25).

Eu nem vou saber de quem peguei, eu era traveco da Atlântica, nem esquentei a cabeça com isso. Naquela época eu era traveco, aí não tem desse negócio de preservativo, depois não adianta reclamar. (Entrevistado n. 9).

Foi sexual, só não sei de quem peguei porque era motorista. (Entrevistado n. 24).

Foi relação sexual, mas eu não sei de quem foi, porque eu era promíscuo, eu sou homossexual e não me cuidava. Já faz uns quatro anos. (Entrevistado n. 29).

O resultado acima corrobora com o estudo de Okuno et al. (2012), que, ao identificarem a forma de contágio entre idosos com HIV/Aids, constataram um percentual de $66,2 \%$ dos entrevistados que adquiriram a doença através de relação sexual.

No que se refere à forma como se deu a descoberta da doença, a maioria dos entrevistados respondeu que passou mal e assim veio a descobrir. Também houve aqueles que descobriram após exames de rotina a pedido do médico e os que fizeram o exame após o(a) companheiro(a) descobrir a doença. O tempo de contágio dos entrevistados variou de dois a oito anos, como relatado a seguir.

Eu soube que a mulher que eu ficava com ela estava, e fiz o exame antes de aparecer qualquer anormalidade...Eu já fiz o exame pra ver, aí realmente deu o problema, faz uns seis anos. (Entrevistado n. 3).

Eu tava internado por um outro problema, aí a médica deu uma geral no meu sangue lá, aí ela disse que eu tava com o vírus. Faz oitos anos que eu descobri. (Entrevistado n. 28).

Passei mal, desmaiei e aí fizeram muitos exames, até que descobriram, mas demoraram pra descobrir. Eu fiquei em coma muito ruim mesmo, isso já faz uns oito anos. (Entrevistada n. 30).

Meu parceiro começou a dar umas feridas no pênis, aí ele foi no médico, o médico examinou e deu positivo. Aí me chamou para fazer o exame também, eu fiz dois exames e deu negativo, no terceiro deu positivo. Isso já faz oito anos. (Entrevistada n.11).

Quando questionados sobre qual seria a razão de os casos de HIV/Aids em idosos estarem aumentando, os entrevistados acreditam que esse fato esteja ligado à falta de informação e de prevenção por parte dos idosos e, até mesmo, por acreditarem que eles estão livres de se contaminarem, como pode ser visto nas falas a seguir: 
Os idosos são ignorantes também porque acham que com eles não acontece nada. (Entrevistado n. 1).

Falta de informação e pode ser descuido mesmo também. (Entrevistado n. 29).

Falta de informação e prevenção, né (Entrevistada n. 7).

Eu acho que é falta de prevenção e excesso de confiança. (Entrevistada n. 19).

Como destaca Lôbo (2011), é comum ver os pacientes idosos justificarem sua condição de soropositividade usando vários fatores, dentre eles a falta de informação sobre como se prevenir do HIV, juntamente com a idéia de que a aids é uma doença do outro, que não vai acontecer consigo.

Ao serem questionados se já se sentiram discriminados por causa da doença, dos 33 entrevistados, seis relataram que sim. Esse preconceito ficava evidente no fato de alguns amigos terem se afastado, de os entrevistados terem perdido o emprego ou tendo em vista comentários que algumas pessoas fizeram a respeito.

Os 27 entrevistados que responderam que nunca sofreram preconceito relacionaram a situação ao fato de não contarem para ninguém ou quase ninguém sobre a doença. Para eles, a questão do sigilo acarreta a ausência do preconceito das pessoas. As falas a seguir expressam o que pensam os entrevistados.

Até que já, porque uma vez eu fui arrumar um serviço com uma mulher que era conhecida, aí ela ficou sabendo e não quis mais, achou que eu ia contaminar a família dela. Aí eu até evito de falar. (Entrevistada n. 7).

Sim, reagi e quase matei a pessoa, não sei como descobriram no prédio, aí eu mudei de lá. (Entrevistada n. 15).

Não, porque não é muita gente que sabe não, só gente mais chegada assim que eu falo. Porque eu tive que falar, não pude guardar só para mim. (Entrevistada n. 10).

Demais, eu me sinto muito triste, muito revoltada. Eu já perdi muita amizade, sabe, porque se eu vejo que as pessoas me discriminam eu afasto. (Entrevistada n. 23).

Não, porque eu não falo muito, não conto para ninguém. A própria doutora tá sempre me falando que eu não tenho que falar não, não tem necessidade, falo para alguém que eu considero, que você sabe que vai te respeitar e tudo mais. Eu nunca fui discriminado não. (Entrevistado n. 5).

Já sim, mas foi no olhar. Verbalmente eu nunca fui, nunca ninguém falou nada comigo, mas eu já fui dispensado do trabalho porque eu 


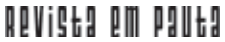

\} HIV NA TERCEIRA IDADE - SILVA, A. O.; LORETO, M. D. S.; MAFRA, S. C. T. \}

DOI 10.12957/REP.2017.30380

contei que tinha a aids, foi tudo sutilmente, mas foi por causa da doença, porque eu trabalhava muito bem. (Entrevistado n. 29).

Silva (2009) afirma que a principal estratégia adotada pelos idosos é a tática do silêncio, do segredo e da ocultação da doença, como forma de evitar situações de estigma e discriminação, que ocorrem de forma mais evidente nas relações familiares e na vida cotidiana por meio de diversos constrangimentos.

Ao serem questionados sobre o preconceito que as pessoas têm com relação a aids, todos os entrevistados foram enfáticos ao afirmarem que se trata de uma besteira que não devia existir e que faz muito mal para as pessoas que possuem a doença, uma vez que elas se sentem obrigadas a omitir a soropositividade e, assim, passam a ser mais solitárias.

É uma bobeira, não devia existir isso, as pessoas sentem pena da gente, é muito triste. (Entrevistado n. 3).

Acho que é uma besteira muito grande e faz muito mal para quem tem a doença esse preconceito. (Entrevistado n. 6).

Eu acho uma besteira, não precisa não, doença não precisa de preconceito não. (Entrevistada n. 10).

Hoje em dia todo mundo tem preconceito, uma coisa que não tem nada a ver, porque o problema é meu, eu que tenho que me cuidar. Se eu te abraçar não vai pegar. (Entrevistada n. 15).

Para os entrevistados, o preconceito direcionado às pessoas com HIV/Aids não é maior quando é um idoso que tem a doença. Eles acreditam que seja igual para todos, e isso está ligado ao fato de o preconceito estar relacionado à doença e não à faixa etária de ocorrência, o que nos remete ao estigma que a doença carrega.

Quando indagados sobre como tem sido o tratamento, os idosos relataram que tem sido bom; no entanto, algumas reações são bastante intensas no início, o que gera alguns incômodos.

Com relação às principais políticas de controle e prevenção do HIV/Aids, os entrevistados declararam já ter visto na televisão, no SAE, nos hospitais e escutado no rádio informações acerca do uso de preservativo. Contudo, para eles, essas informações são passadas somente em algumas épocas do ano, como o carnaval e no dia mundial de combate à aids. Os entrevistados acreditam que seria muito importante estarem divulgando mais e direcionando as campanhas para todas as idades, pois, conforme observado nas respostas de alguns, diversas campanhas são direcionadas apenas para os jovens. Alguns também acreditam que a descoberta de uma vacina contra a doença seria importante.

As falas a seguir mostram os depoimentos dos idosos. 
Na televisão mostra alguma coisa, agora parou, mas no início tava mostrando. Eu acho que a televisão devia divulgar mais, porque é onde todo mundo tem acesso. Devia ter mais palestras também ou reunião em cada município, porque muitas vezes passa despercebido e as pessoas esquecem. (Entrevistado n. 29).

Só vejo na televisão e escuto no rádio de vez em quando. Eu vi na televisão que ia ter uma vacina que acaba com essa doença, aí ia ser importante porque ajudaria muita gente. (Entrevistado n.14).

Antes fazia mais propaganda, agora quando é a época do HIV é que eles falam mais. Eu leio algumas coisas no jornal, também devia alertar nas escolas e as pessoas ficarem mais conscientes também. (Entrevistada n. 7).

Tem falando sobre relacionamento com camisinha, sobre usar drogas na veia, essas coisas. Devia ter mais alertas na televisão, que é mais útil pra contato. (Entrevistado n. 6).

Falam muito que tem que usar camisinha e sobre o negócio do sangue; se acontecer, se tiver cortado, não fazer contato com outra pessoa, se o colega tiver machucado, não usar o mesmo aparelho que o outro, que vai passar para o outro. Eu vejo quando passa na televisão porque eu gosto muito de assistir um jornal. Os rapazes e as meninas, essas meninas de 17 anos, que não podem ver um homem, que não procura nem saber se eles têm uma doença ou não, e elas não tão nem aí, e os rapazes, pior ainda, deviam alertar, porque eles não tão nem aí. (Entrevistada n. 4).

Como destacam Araújo, Moura e Cardoso (2009), a escassez de campanhas de educação e prevenção direcionadas para os idosos é um fator determinante para que essa população fique menos informada e, assim, não se preocupe com a prevenção do HIV.

\subsection{As repercussões do HIV/Aids sobre os domínios da vida dos idosos}

No que se refere às mudanças que o HIV/Aids acarretou nos domínios da vida dos idosos, especificamente no que diz respeito ao trabalho, para 20 entrevistados não ocorreu nenhuma mudança, uma vez que estes já não estavam mais trabalhando. No entanto, para os demais, a doença gerou modificações ligadas à dificuldade em conseguir trabalhar devido a fraquezas e outros problemas consequentes ao uso do coquetel. Além disso, alguns se aposentaram após o diagnóstico. A seguir, alguns depoimentos dos entrevistados:

No mesmo dia que eu descobri eu já fui pegando os papel, já fui aposentando. (Entrevistado n. 9). 
Eu achei diferença sim, porque a gente, depois que pega isso, a gente sente muita coisa, inclusive o remédio que a gente toma dá um efeito terrível na gente, muito ruim. Aí eu achei a diferença sim, antes de eu ter e depois, só assim de sentir mais coisas, assim que a gente vai sentindo. (Entrevistada n. 11).

Eu fiquei inútil pra trabalhar. (Entrevistado n. 12).

Eu era motorista de caminhão, aí eu fui impossibilitado de dirigir, aí fui mexer no quintal da minha mãe, fui cuidar disso. (Entrevistado n. 24).

As falas dos entrevistados acima podem ser explicadas por Lopes et al. (2011) ao relatarem que uma dificuldade enfrentada no trabalho pelas pessoas HIV+ é o fato de que muitos empregadores não os admitem, não só pelo preconceito, mas também porque os pacientes precisam faltar ao emprego para ir a consultas ou por causa dos efeitos colaterais, que acabam interferindo na produtividade dos indivíduos.

Com relação à vida familiar, 19 idosos responderam que não houve nenhuma mudança depois da descoberta da doença; cinco declararam que sentiram alterações relacionadas ao comportamento de alguns familiares; oito entrevistados relataram não terem contado para ninguém e um disse não ter família, como mostram as falas a seguir:

Mantive segredo, ninguém sabe. Eu já prefiro deixar só eu preocupado e não pôr a família preocupada. Irmã, ninguém sabe, se souber, sabe por fora e não por mim, não contei nada a ninguém. (Entrevistado n. 3).

Sim, eu fiquei sendo mais paparicado. (Entrevistado n. 8).

Pelos meus filhos não, mas por algumas irmãs, eu sinto que agora eu sou um pouquinho mais afastada. (Entrevistada n. 23).

Percebi que fecharam pro meu lado. (Entrevistado n. 18).

Eu não contei pra ninguém lá em casa, porque não ia adiantar nada também, então mantive segredo. Escondo meus medicamentos e tomo tudo escondido. (Entrevistado n. 2).

Alencar (2012) explica que, frente à realidade de preconceito e discriminação, além do sigilo em relação à doença, os idosos geralmente contam sobre sua condição sorológica apenas para algumas pessoas do meio familiar. Isso, por um lado, traz dificuldades para o idoso no enfrentamento da doença, uma vez que a família constitui uma das mais importantes redes de apoio psicossocial.

No que tange à saúde, 22 entrevistados relataram não terem sentido nenhuma mudança antes e depois da descoberta da doença. Os demais sentiram uma piora relacionada às reações aos medicamentos, bem como 
aos sintomas acarretados pelo HIV/Aids. Essas questões podem ser explicitadas a seguir:

Sinto fraqueza geral, principalmente antes de comer alguma coisa. Muita fraqueza, falha de memória, isso tudo depois da doença. (Entrevistado n. 6).

Senti muita [diferença], inclusive eu sinto assim, mais dores, né, igual eu tô te falando, sinto muita dor. Sobre sexo eu não faço mais, eu acho que não vale apena e também tenho medo de sentir dor. (Entrevistada n. 11).

É muita coisa, antes eu não tinha nada e depois que eu tive essa doença apareceu as coisas. O meu pulmão ficou danificado, sinto muita falta de ar por causa do pulmão. (Entrevistado n. 12).

Não, porque mais o que eu tenho agora mesmo é da idade, né. Porque os ossos começam a doer, problema de coluna toda a vida eu tive. (Entrevistada n. 25).

Como pode ser visto nos relatos acima, apesar de alguns idosos afirmarem que sentiram uma piora em sua saúde após o diagnóstico, outros acreditam que as enfermidades que sentem atualmente estão ligadas à idade, e não ao HIV/Aids. No entanto, o uso do coquetel, juntamente à soropositividade, acarreta diversos problemas e complicações relacionados à saúde do paciente.

No que diz respeito às modificações ocorridas quanto à prática religiosa, 26 idosos relataram não terem sentido nenhuma mudança no que se refere à busca pela religião, uma vez que aqueles que frequentavam a igreja relataram continuarem indo do mesmo modo. O restante dos idosos, entretanto, afirmaram que buscaram mais a religiosidade como forma de tentar superar a doença. Os trechos dos depoimentos a seguir confirmam o exposto:

Mudou, acho que a gente pensa mais em Deus. Eu não sou muito de ir à igreja não, mas aí a gente se entrega mais a Deus, pede mais força. Eu tenho certeza que Deus vai me curar. (Entrevistada n. 7).

Não mudou, eu sempre fui muito religiosa, sempre tive muita fé. A fé que me segura de pé. (Entrevistada n. 20).

Não mudou nada, vou a mesma coisa, quando tenho vontade. (Entrevistado n. 33).

Agora eu tô buscando mais. Tem vez que não dá pra ir não, aí eu fico até chateado, mas ligo o radinho na religião. (Entrevistado n. 12).

As falas dos idosos confirmam o relato de Saldanha, Araújo e Sousa (2009) ao afirmarem que a crença religiosa se torna, para a maioria dos 


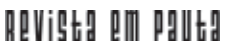

\} HIV NA TERCEIRA IDADE - SILVA, A. O.; LORETO, M. D. S.; MAFRA, S. C. T. \}

DOI $10.12957 /$ REP.2017.30380

idosos, uma fonte de esperança, uma forma de enfrentamento e alívio para o sofrimento, o medo e a angústia.

No que se refere às alterações percebidas com relação às amizades, 18 entrevistados relataram não ter contado para nenhum amigo, 11 disseram que os amigos que sabem não manifestaram nenhuma mudança, um afirmou não ter amigos e o restante sentiu um afastamento dos amigos que sabiam da condição soropositiva, como demonstram as falas a seguir:

Das minhas amigas ninguém sabe, não tive coragem de contar para ninguém, porque hoje em dia você pensa que tem amizade, você não tem. As vezes você conta, a pessoa fala pra frente, a pessoa tem preconceito. (Entrevistada n. 4).

Tem uma amiga minha que se afastou um pouco. (Entrevistada n. 15).

Eu não tenho amigos, sou sozinha mesmo. (Entrevistada n. 26).

Não, quem sabe me trata normal, quem eu não confio muito eu não comento. (Entrevistado n. 8).

Estudo realizado por Silva et al. (2012) com pacientes a partir de 60 anos em atendimento no SAE de Divinópolis (MG), durante o ano de 2012, corrobora com esse resultado. Isso porque, entre os entrevistados, destacaram-se aqueles que não revelaram o diagnóstico para os amigos, uma vez que sentiam medo relacionado ao preconceito, ao afastamento das pessoas, além de se preocuparem em perder o respeito dos amigos. Dessa forma, evidencia-se o esforço dos idosos em manter segredo do diagnóstico.

Em se tratando de situação financeira, 22 entrevistados afirmaram que não houve mudanças em sua situação, uma vez que os medicamentos são oferecidos pelo SUS. Já o restante afirmou ter tido aumento de gastos relacionados à alimentação e a alguns medicamentos que, às vezes, precisam comprar.

Não, porque os remédios são por conta do SUS. (Entrevistado n. 3).

Tô gastando mais muncadim, né. De vez em quando o médico passa um remédio pra comprar. (Entrevistado n. 12).

Não, eu gastei igual. (Entrevistada n. 23).

Já em relação ao tempo livre para o lazer, 21 idosos relataram não terem percebido nenhuma modificação, pois alguns afirmaram não gostarem de sair de casa, enquanto que outros disseram que já tiravam um tempo para lazer antes da doença. Contudo, 12 idosos disseram que agora têm mais tempo livre, uma vez que não estão mais trabalhando e, assim, podem sair quando quiserem. Os relatos abaixo evidenciam essas questões: 
\} HIV NA TERCEIRA IDADE - SILVA, A. O.; LORETO, M. D. S.; MAFRA, S. C. T.

DOI $10.12957 /$ REP.2017.30380

Antes eu trabalhava, né, agora eu posso passear todo dia. Todo dia de manhã vou na casa que meu pai deixou e à noite volto para a casa da minha irmã. (Entrevistado n. 1).

Não mudou, não gosto de sair, nunca gostei, se eu não for para a igreja o resto eu não gosto. (Entrevistada n. 10).

Eu sou uma pessoa muito tranquila e então to a mesma coisa, não mudei nada não, mas eu sou um cara muito de casa, mais caseiro, não gosto de bagunça. (Entrevistado n. 17).

Eu continuo saindo e passeando do mesmo jeito. Eu não aguento ficar quieta dentro de casa, não nasci para ser presa. (Entrevistada n. 25).

Isso agora eu tenho, né, porque antes trabalhava. (Entrevistado n. 24).

Agora eu tenho tempo para o lazer, porque eu já aposentei mesmo, posso sair, aproveitar. Todo dia eu vou jogar carteado, isso aí me ajudou muito também porque prende o tempo. (Entrevistada n. 21).

Para Antunes (2012), a importância do lazer na terceira idade está relacionada ao envelhecimento com autonomia e independência, além de qualidade de vida, o que acarreta uma diminuição nas preocupações dos idosos com os agravos na saúde.

Por fim, em relação aos vizinhos, 24 entrevistados afirmaram que nenhum vizinho sabe da doença, enquanto que seis relataram não terem percebido nenhuma modificação no comportamento dos vizinhos que sabem. Os demais declararam ter sentido um distanciamento dos vizinhos, bem como certa discriminação.

Minha vizinhança tem sido boa para mim, graças a Deus. Lá onde eu moro, tem dez anos que eu moro lá, é tudo tranquilo. (Entrevistado n. 9).

Não, lá meus vizinhos que sabe continuou a mesma coisa comigo, não teve mudança não. (Entrevistada n. 11).

Tem uns conhecido meu lá que sabe. Antes eles brincavam comigo, mas agora a gente nota [mudança], senti um pouco de diferença. (Entrevistado n. 12).

Acredito que eles saibam, porque uma vez eu chamei a ambulância porque eu estava em crise de pânico e para a ambulância chegar até mim eu tive que falar que eu tinha aids. Mas eu não senti nenhuma diferença no comportamento deles não, por sinal são ótimos vizinhos. (Entrevistada n. 15).

Não, os vizinhos de conversa fiada eu afastei de tudo, eu faço de conta que eles estão falando a maior calúnia, faço de conta que não sei de nada. Tem uma vizinha que a filha dela morreu com HIV e quando ela descobriu que eu tava contou para um monte de gente, então eu fiquei 
chateada com ela porque eu ajudei ela muito. O pior que as outras pessoas nunca tiveram confirmação de mim tem gente que não acreditou nela e acreditou em mim, acham que eu não tenho porque ela é conversa fiada, por causa da língua dela. Eu gostava dela, mas aí eu preferi cortar, não teve jeito. (Entrevistada n. 21).

Demais, eu senti discriminação mesmo, você sai eles ficam olhando. Eu fiquei muito tempo sem o passe livre por vergonha, porque ficava todo mundo de olho querendo saber o que eu tinha. (Entrevistada n. 23).

Estudo realizado por Cerqueira (2014) com idosos que vivem com HIV/Aids demonstrou resultado semelhante ao registrar, pelo relato dos idosos, que é comum que eles mantenham segredo sobre a sua condição sorológica para os vizinhos, considerando que o segredo pode garantir a continuidade da estrutura das redes sociais.

\subsection{As repercussões do HIV/Aids sobre o funcionamento familiar do idoso}

No que se refere ao funcionamento familiar dos idosos, vale ressaltar que, dos 33 entrevistados, doze moravam sozinhos, oito residiam com os filhos(as), quatro com os irmãos, quatro com o cônjuge ou companheiro, dois com a mãe, um com o sobrinho, um com a neta e um no Grupo Espírita de Ajuda aos Enfermos (Gedae).

Ao serem questionados sobre as mudanças que ocorreram na composição familiar em relação ao número de membros, antes e depois da descoberta da doença, 21 entrevistados relataram não ter ocorrido nenhuma alteração; ou seja, continuaram vivendo sozinhos ou com os membros com quem já viviam. No entanto, os demais relataram ter ocorrido modificações, uma vez que foram morar com outros parentes ou até mesmo passaram a viver sozinhos, devido ao fato de os filhos terem se casado ou por terem ficado viúvos, como pode ser visto nas falas a seguir.

Antes eu morava com o meu irmão, aí meu irmão morreu e eu fui para a casa da minha irmã porque ela ficou com medo que eu ficasse em depressão lá sozinho. (Entrevistado n. 1).

Quando eu descobri, morava com meus dois filhos e ainda moro com eles. (Entrevistada n. 4).

Antes de eu descobrir a doença eu morava com minha esposa e com uma neta dela. Agora, depois que fiquei viúvo, moro sozinho. (Entrevistado n. 17).

Antes eu morava sozinha e depois eu arrumei um companheiro. Aí, quando eu separei desse companheiro, eu fui morar com a minha filha. (Entrevistada n. 21). 
Antes eu morava na rua, né, agora moro no Gedae. (Entrevistada n. 26).

Camargos e Rodrigues (2008) esclarecem que, apesar de a terceira idade não ser sinônimo de doenças e incapacidades, sabe-se que nessa fase da vida as pessoas acabam estando mais suscetíveis a problemas de saúde e, em consequência disso, precisam de mais apoio. Dessa forma, os idosos que vivem com outras pessoas, parentes ou não, encontram-se aparentemente mais amparados em caso de problemas de saúde ou nas atividades da vida diária. Por outro lado, os idosos que moram sozinhos estão mais vulneráveis e desprovidos de apoio diante de dificuldades relacionadas à saúde.

Em relação às mudanças nas normas e regras que regulam o comportamento e a vida da família, para 28 entrevistados não ocorreu nenhuma alteração; dois afirmaram ter havido modificações relacionadas a uma maior higiene e cuidado entre os moradores da sua casa, bem como uma maior aproximação entre os membros, pois todos buscam estar mais unidos; e dois afirmaram que em sua casa nunca tiveram essas normas, uma vez que é cada um por si.

Lá em casa não tem disso não, nunca teve. É cada um por si mesmo. (Entrevistado n. 1).

A gente cuida mais, há mais higiene, lava a mão toda hora, aquela coisa toda, né. (Entrevistado n. 8).

Não mudou não, continua reunido. Sempre tivemos costume de almoçar junto, tudo reunido. (Entrevistada n. 11).

Agora que eu coloquei [regra], antes não tinha não, depois que minha irmã faleceu, então agora eu coloquei regra em tudo. A gente tenta ficar sempre perto, almoçar junto. (Entrevistada n. 20).

No que tange às mudanças nas formas de interação entre os membros da família, notou-se que 26 idosos relataram não ter ocorrido nenhuma modificação antes e depois da descoberta da doença, enquanto que seis perceberam alterações no comportamento de seus familiares.

Não mudou não, continua tudo do mesmo jeito, mas percebo que minha irmã toma mais cuidado, né. (Entrevistado n. 1).

Antigamente, quando eu não tinha, era mais afastado, agora eles tão chegando mais, sabe. Contei pra todo mundo no mesmo dia, não é tão difícil, é só tratar agora. (Entrevistado n. 9).

Tem uma irmã minha e um irmão que afastou um pouquinho de mim, conversa comigo, mas é de longe, e afastou. Assim a gente nota, não é igual. (Entrevistado n. 12).

Nossa interação é boa, estou mais próxima dos meus filhos. Meus filhos melhoraram muito. (Entrevistada n. 15). 


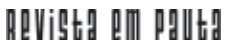

\} HIV NA TERCEIRA IDADE - SILVA, A. O.; LORETO, M. D. S.; MAFRA, S. C. T. \}

DOI 10.12957/REP.2017.30380

Para Jesus, Ribeiro e Gonçalves (2012), as reações da família em relação ao individuo portador do HIV podem ser influenciadas pelos significados que a cultura atribui à doença, fazendo com que, assim, os idosos sejam discriminados e excluídos do grupo familiar.

Em relação ao comportamento dos membros da família frente à descoberta da doença, predominaram, nas respostas dos entrevistados, os sentimentos de compreensão, susto e, em alguns casos, revolta, como demonstram as falas abaixo:

Minha irmã não se importou porque disse que já sabia que isso um dia ia acontecer. Porque antes eu saía com umas mulheres que ela falava que não prestavam. Mas os meus irmãos que sabem da doença me compreenderam e me ajudaram. (Entrevistado n. 1).

Não teve revolta não, teve compreensão e foi um susto, né, porque é normal de levar um susto. (Entrevistado n. 5).

Compreensão eu vi em alguns, os familiares mais próximos. Os outros eu nem fui na casa deles contar. (Entrevistado n. 9).

A minha menina, não sei se ela pensou que eu ia morrer assim de repente, ela tava morando no Rio, aí quando ela descobriu até chorou, se desesperou, aí ficaram, mas vem morar com a gente, aí eu falei, não preciso morar com ninguém, sei fazer minhas coisas. Acho que eles só se viram revoltados por causa desse moço [quem passou o HIV], né, mas depois eles fizeram amizade com ele, continua amizade do mesmo jeito. (Entrevistada n. 10).

Meus filhos ficaram revoltados, mas foi com o meu marido, né, por causa do cara ter feito isso comigo, né, aí foi a revolta com ele, mas só isso. Comigo foi compreensão. (Entrevistada n. 11).

Nunca me falaram nada, mas eu senti que eles esfriaram um pouco; um pouco não, muito. (Entrevistado n. 18).

De acordo com Vieira, Alves e Sousa (2012), a família exerce um papel muito importante na vida do idoso. No entanto, cada família tem uma forma de reagir diante do diagnóstico de soropositividade, e isso vai depender de sua crença, cultura e regras. Dessa forma, é comum ver até mesmo o afastamento dos membros da família e de pessoas do convívio social do idoso. Isso é consequência da dificuldade da família em aceitar a doença, com medo da contaminação, da diminuição da renda devido aos gastos com o tratamento, da falta de conhecimento a respeito da doença e, até mesmo, dos tabus relacionados à sexualidade na terceira idade.

Sobre as relações de afeto e apoio, os idosos entrevistados afirmaram que recebiam sim de seus familiares e que não houve diferença, de modo que eles sentem que as famílias estão sempre prontas a ajudar e apoiar. 
No entanto, destacaram-se dois entrevistados que acreditam não receber de nenhum de seus familiares essas relações.

Dos meus familiares é assim foi, mas menos, já dos meus amigos eu recebo mais. (Entrevistado n. 5).

Também não mudou, só com a minha irmã, porque nosso gênio não dá certo. (Entrevistado n. 14).

Eu não sinto não. Não recebo. (Entrevistado n. 18).

A minha irmã, devido ela ser doente, ela sempre jogava na minha cara, me chama de aidética. Já com a outra irmã e o sobrinho teve relação de afeto e apoio sim, sempre teve. (Entrevistada n. 20).

Como afirmam Galvão e Paiva (2011), a rede social de apoio à pessoa vivendo com o HIV/Aids é importante para que ela não se sinta sozinha no enfrentamento de uma doença com as peculiaridades do HIV, marcada pelo preconceito e o abandono. O suporte da família faz o portador do HIV encarar a doença com mais coragem e continuar vivendo sua vida, tendo uma doença que exige cuidados diários como qualquer outra doença crônica.

Ao serem questionados se já haviam vivenciado algum conflito devido à doença, destacou-se entre os entrevistados a resposta negativa (73\%); ou seja, a maioria nunca teve conflito com ninguém em função da soropositividade. No entanto, também surgiram algumas respostas positivas, estando esses conflitos associados às pessoas ou membros familiares que falaram alguma coisa que o entrevistado não havia gostado, ou ao parceiro, que tinha a doença e não contou.

Sim, quando eu fiz o exame aí que eu soube, eu cheguei para ele [parceiro] e falei. Ele pediu perdão, falou que não sabia que tinha, aí eu chorei e perdoei, mas falei que não dava pra gente continuar mais. (Entrevistada n. 4).

Não, inclusive com a própria pessoa que eu sei que transmitiu, nunca inferi a pessoa em nada. (Entrevistado n. 8).

Sim, foi com uma pessoa conhecida que fez um comentário e a outra pessoa veio me contar, então eu disse que se ela continuasse com esses comentários eu iria processar, aí ele parou. (Entrevistada n. 15).

Com o companheiro, eu tive, porque tava muito desesperada, aí ele falou: que que tem? Não passaram pra mim também? Aí me deu uma revolta terrível. (Entrevistada n. 19).

Teve uma vez que um besta que falou lá no mercado que eu tava, aí eu peguei e perguntei porque ele tava falando de mim. Ele não era nada 
meu não, conhecido só, não era amigo nem nada, aí eu fui lá e dei um pega nele, pra ele calar a boca e cuidar da vida dele. Foi só esse conflito, mais nada. (Entrevistada n. 21).

Como esclarecem Botti et al. (2009), ao se descobrir portador de uma doença incurável, a pessoa vivencia conflitos que são comuns e fazem parte de qualquer situação desconhecida. O que diferencia é a maneira como cada indivíduo vivencia esses momentos, podendo haver situações de negação, raiva, depressão, isolamento e aceitação.

Em relação a como tem sido o envolvimento familiar no enfrentamento da doença, a maior parte dos idosos relatou que foi de aproximação; no entanto, houve aqueles que relataram um distanciamento de alguns membros da família.

Dos que sabem ninguém afastou, mas ninguém ajuda também, só essa minha irmã que moro com ela, parece que os outros não compreendem muito bem. (Entrevistado n. 1).

De todos os irmãos, teve um que mais se afastou. Ele não tem um diálogo comigo sobre esse problema, só Deus e eu para o problema. (Entrevistado n. 6).

No princípio um susto, né, todo mundo ficou meio lá, meio cá, mas tudo bem. Tenho apoio emocional, psicológico, tudo, né. Acho que a família é tudo na vida. (Entrevistado n. 8).

Todo apoio, tudo que precisar, tão tudo de acordo, é tudo o melhor possível. Não senti afastamento nenhum. (Entrevistado n. 16).

Eles me amam de todo coração. Eu tenho todo apoio emocional. (Entrevistada n. 20).

Quando eu descobri eu tinha visita todo dia [no hospital], minhas amigas vieram de longe pra me ver, rezavam o terço comigo, meu filho me deu total apoio, eu tenho uma netinha também que eu amo demais e minha nora é apaixonada comigo, não tenho o que reclamar. Eu recebo todo apoio do mundo e tenho total compreensão deles. (Entrevistada n. 30).

Tenho apoio de todos os lados, inclusive quando eu falo com minha irmã que ainda não tomei o remédio ela fica doida, fica me perguntando se eu tomei o remédio. Graças a Deus a minha família é a base de tudo. (Entrevistado n. 29).

Como pode ser visto nos relatos acima, para o portador do HIV/ Aids o apoio familiar é de grande importância. Botti et al. (2009) afirmam que, apesar do sofrimento ao saber do diagnóstico, a união e a afetividade se mantêm em alguns casos. Dessa forma, ao perceber a colaboração e a compreensão da família, o individuo passa a se sentir fortalecido e protegido. 


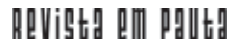

\} HIV NA TERCEIRA IDADE - SILVA, A. O.; LORETO, M. D. S.; MAFRA, S. C. T. \}

DOI $10.12957 /$ REP.2017.30380

Por fim, para os idosos entrevistados, as principais redes de apoio, formais e informais, às quais eles recorreram foram o SAE e a família, ou apenas um membro da família. A seguir, algumas falas dos entrevistados:

Só o SAE, porque eu acho que problema de doença se resolve com instituição de doença, hospital. Tem que procurar o lugar certo. (Entrevistado n. 14).

Foi aqui no $\mathrm{SAE}$, eu tive todo apoio daqui, né. Família e amigos não contei para ninguém não (Entrevistada n. 10).

Primeiro, no dia, quem tava comigo era minha filha, e de imediato eu liguei pros meninos que eu trabalho com eles e falei na mesma hora, eu não gosto de nada escondido porque eu não preciso esconder nada de ninguém. Aí tem o SAE também, né. (Entrevistado n. 16).

Primeiro lugar que eu fui é aqui no SAE, aí da família só minha irmã que morreu sabia e o filho dela também sabe e me dá o maior apoio (Entrevistada n. 29).

Como pode ser visto nos depoimentos mencionados, a rede mais recorrida foi o $\mathrm{SAE}$, uma vez que alguns entrevistados não contaram para ninguém sobre a doença. Dessa forma, fica evidente a importância dessa rede para as pessoas que vivem com o HIV/Aids, já que, em algumas situações, essa pode ser a única rede de apoio disponível, com a qual os idosos mantêm uma relação de confiança e onde podem falar abertamente sobre a doença.

\section{Conclusão}

Este estudo buscou compreender quais são os fatores intervenientes para a aquisição da doença, além das repercussões do HIV/Aids nos domínios da vida e no funcionamento familiar do idoso. Assim, identificou-se que, em relação ao contágio, a maioria se deu de forma sexual, o que nos leva a refletir sobre a falta do uso de preservativos, bem como sobre a necessidade de campanhas direcionadas para a faixa etária de 60 anos ou mais, com o intuito de estar sempre alertando sobre a importância do uso dos preservativos. Além disso, é importante destacar que, para a maioria dos idosos entrevistados, não ocorreram mudanças significativas em seus domínios da vida.

Nas questões relacionadas ao funcionamento familiar, é importante destacar o fato de que alguns idosos mantinham sigilo acerca da doença e, devido a isso, não vivenciarem mudanças em seu relacionamento com a família. Contudo, para os idosos que afirmaram terem contado para a família sobre a doença, a maior parte se sentiu acolhida, o que contribuiu para o 
enfretamento da doença. Ou seja, para o portador do HIV/Aids, enfrentar a doença sozinho gera diversos sentimentos ruins; desse modo, a falta de apoio da família e de amigos traz consequências negativas na adesão ao tratamento, no isolamento do paciente e na dificuldade que o idoso tem de buscar ajuda.

Assim, pode-se concluir que o preconceito e a falta de informação que as pessoas têm sobre a aids levam os portadores do HIV/Aids a esconderem sua condição soropositiva, devido ao medo do julgamento e de se sentirem discriminados. Especialmente com os idosos, a vergonha é um fator importante para que esses escondam o diagnóstico de todos. Dessa forma, fica clara a necessidade de campanhas direcionadas para essa faixa etária, com a finalidade de quebrar os tabus que existem acerca da sexualidade na terceira idade. Assim, os idosos podem se sentir mais à vontade para falarem com outras pessoas sobre o assunto, bem como para buscarem apoio junto das suas redes de convivência, especialmente as familiares. 


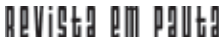

I HIV NA TERCEIRA IDADE - SILVA, A. O.; LORETO, M. D. S.; MAFRA, S. C. T.

DOI 10.12957/REP.2017.30380

\section{Referências}

ADDAMS, J. Age and relative importance of major life domains. Journal of Aging Studies, v. 19, n. 4, 2005.

ALENCAR, R. de A. O idoso vivendo com HIV/AIDS: a sexualidade, as vulnerabilidades e os enfrentamentos na atenção básica. 2012. Tese (Doutorado)- Escola de Enfermagem, Universidade de São Paulo,São Paulo, 2012.

ALMEIDA, M. R. de C. B. de; LABRONICI, L. M. A trajetória silenciosa de pessoas portadoras do HIV contada pela história oral. Caderno de Saúde Coletiva, v. 12, n. 1, 2007.

ANDRADE, H. A. dos S.; SILVA, S. K. da; SANTOS, M. I. P. de O. Aids em idosos:vivências dos doentes. Esc Anna Nery (impr.),v. 14, n. 4, 2010.

ANTUNES, E. Saúde do idoso: políticas de saúde e assistência social e as ações existentes nas $25^{\text {a }}$ e $26^{a}$ Secretaria do Desenvolvimento Regional (SDR).Dissertação (Mestrado) -Desenvolvimento Regional,Universidade do Contestado (UNC), Canoinhas, 2012.

ARAÚJO, V. L. B. de, et al. Características da Aids na terceira idade em um hospital de referência do Estado do Ceará, Brasil. Revista Brasileira de Epidemiologia, v. 10, n.4, 2007.

ARAÚJO, C. L. de O.; MOURA, L. F.; CARDOSO, N. A. Caracterização do portador de HIV/AIDS acima de 50 anos. Revista Kairós Gerontologia, v. 12, n. 2, 2009.

BARDIN, L. Análise de conteúdo. Lisboa: Edições 70, 2011.

BARROS, N. B.; GUIMARÃES, C. M.; BORGES, O. de S. Políticas de saúde e prevenção ao HIV/Aids no Brasil (1982-2012). Estudos, v. 39, n. 4, 2012.

BERNARDI, J. Vulnerabilidade social e Aids:o desafio da prevenção em tempos de pauperização da epidemia. Porto Alegre: CNBB Pastoral de DST/ Aids, 2005.

BOTTI, M. L. et al. Convivência e percepção do cuidado familiar ao portador de HIV/Aids. Rev. Enferm,v. 17, n. 3, 2009.

BRAY, J. H. Family assessment: current issues in evaluating families. Journal of Family Relations, v. 44, n. 4, 1995.

CAMARGOS, M. C. S.; RODRIGUES, R. N. Idosos que vivem sozinhos: como eles enfrentam dificuldades de saúde. In: XVI ENCONTRO NACIONAL DE ESTUDOS POPULACIONAIS. Caxambu(MG), 2008.

CAREGNATO, R. C. A.; MUTTI, R. Pesquisa qualitativa: análise de discurso versus análise de conteúdo. Texto Contexto Enfermagem, v. 15, n. 4, 2006. CARVALHO, S. M.; PAES, G. O. A influência da estigmatização social em pessoas vivendo com HIV/Aids. Caderno de Saúde Coletiva,v. 19, n. 2, 2011. 


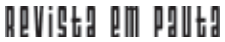

\} HIV NA TERCEIRA IDADE - SILVA, A. O.; LORETO, M. D. S.; MAFRA, S. C. T. \}

DOI 10.12957/REP.2017.30380

CELEDÔNIO, L. P.; ANDRADE, L. S. de. Aids na terceira idade: sentimentos, percepções e perspectivas de mulheres vivendo com HIV/Aids. Serviço Social e Saúde, v. 13, n. 1, 2014.

CERQUEIRA, M. B. R. Idosos vivendo com HIV/Aids :vulnerabilidade e redes sociais em Belo Horizonte (MG). 2014. Tese (Doutorado) - Centro de Desenvolvimento e Planejamento Regional (Cedeplar) da Faculdade de Ciências Econômicas da Universidade Federal de Minas Gerais (UFMG), Belo Horizonte, 2014.

DINIZ, R. F.; SALDANHA, A. A. W.; ARAÚJO, L. F. de. Crenças e opiniões no cuidado de idosos com Aids: um estudo exploratório. Revista Brasileira em Promoção da Saúde, v. 23, n. 3, 2010.

FEIJÓ, M. R. Família e rede social. In: CERVENY, C. M. O. (Org.). Família e rede social. São Paulo: Caso do Psicólogo, 2006.

GALVÃO, M. T. G.; PAIVA, S. de S. Vivências para o enfrentamento do HIV entre mulheres infectadas pelo vírus. Rev. Bras. Enferm, v. 64, n. 6, 2011.

GOMES, S. F.; SILVA, C. M. da. Perfil dos idosos infectados pelo Hiv/Aids: uma revisão. Vitalle, v.20, n.1, 2008.

GUERCIO, P. M. da S. Serviço de Assistência Especializada (SAE).2004. Disponível em: <http://www.pjf.mg.gov.br/secretarias/saude/aids_dst/ servicos.php>. Acesso em: 1 maio de 2016.

JARDIM, L. N. O HIV na terceira idade: o lugar designado ao idoso nas políticas públicas em HIV/Aids e as concepções de profissionais de saúde acerca desta problemática. 2012. Dissertação (Mestrado) - Programa de Pós-Graduação em Psicologia da Universidade Federal de Juiz de Fora, Juiz de Fora, 2012. JESUS, E. de; RIBEIRO, E. M. N.; GONÇALVES, T. M. de B. Aids na terceira idade: uma questão de sexualidade.2012. Disponível em: <http://fugedu. com.br/repositorio/wp-content/uploads/2015/03/AIDS-NA-TERCEIRAIDADE-Uma-Quest\%C3\%A3o-de-Sexualidade.pdf>. Acesso em: 1 maio 2016.

LÔBO, M. P. Vulnerabilidade ao HIV/Aids: representações sociais de idosos residentes em zona rural. Dissertação (Mestrado) - Programa de PósGraduação em Enfermagem e Saúde da Universidade Estadual do Sudoeste da Bahia, Jequié, Bahia, 2011.

LOPES, P. S. D. et al. Qualidade de vida dos pacientes HIV positivo com mais de 50 anos. Rev. da AMRIGS, v. 55, n. 4, 2011.

MINAYO, M. C. de S. Pesquisa social: teoria, método e criatividade. Petrópolis: Vozes, 2012.

OKUNO, M. F. P. et al. Conhecimento e atitudes sobre sexualidade em idosos portadores de HIV/Aids. Acta Paulista de Enfermagem, v. 25, n. 1, 2012. PAULILO, M. A. S. A pesquisa qualitativa e a história de vida. Serviço Social em Revista, v. 2, n. 2, 1999. 


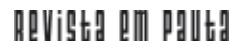

\} HIV NA TERCEIRA IDADE - SILVA, A. O.; LORETO, M. D. S.; MAFRA, S. C. T. \}

DOI 10.12957/REP.2017.30380

SALDANHA, A. A. de W.; FELIX, S. M. F.; ARAÚJO, L. F. de. Representações sobre a Aids na velhice por coordenadoras de grupos da terceira idade. Psico USF,v. 13 n. 1, 2008.

SALDANHA, A. A. W.; ARAÚJO, L. F. A.; SOUSA, V. C. Envelhecer com Aids: Representações, crenças e atitudes de idosos soropositivos para o HIV. Rev. Interamericana de Psicologia, v. 43, n. 2, 2009.

SANTOS, A. F. de M.; ASSIS, M. Vulnerabilidade das idosas ao HIV/Aids: despertar das políticas públicas e profissionais de saúde no contexto da atenção integral: revisão de literatura. Revista Brasileira de Geriatria e Gerontologia, v. 14, n. 1, 2011.

SCHRÖDER, E. F. Idosos e HIV/Aids. In: I CONGRESSO INTERNACIONAL DA FACULDADES EST., São Leopoldo, 2012.

SERRA, A. et al. Percepção de vida dos idosos portadores do HIV/Aids atendidos em centro de referência estadual. Saúde em Debate, v. 37. n. 97, 2013.

SILVA, L.C. et al. Envelhecimento e HIV: impactos psicossociais do diagnóstico de pacientes idosos atendidos no SAE - Serviço de Assistência Especializada - do Município de Divinópolis, Minas Gerais. 2012. Disponível em: <http://www.convibra.com.br/upload/paper/2013/78/2013_78_5816. pdf>. Acesso em: 1 maio 2016.

SILVA, W. A. A experiência de conviver com HIV/Aids na velhice. Tese (Doutorado) -Programa de Pós-Graduação em Psicologia Social do Instituto de Psicologia da Universidade de São Paulo, São Paulo, 2009.

TRIOLA, M. F. Introdução à estatística. Rio de Janeiro: LTC, 2013.

VERGARA, S. C. Métodos de pesquisa em administração. São Paulo: Atlas, 2005.

VIEIRA, G. D. V.; ALVES, T. C. A.; SOUSA, C. M. Análise dos dados epidemiológicos da Aids em idosos no estado de Rondônia, Amazônia Ocidental. J. Bras. Doenças Sex. Transm. v. 14, n. 1, 2012.

Recebido em 02 de agosto de 2016.

Aprovado para publicação em 12 de dezembro de 2016.

DOI 10.12957/rep.2017.30380

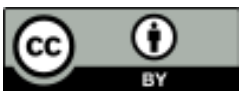

A Revista Em Pauta: Teoria Social e Realidade Contemporânea está licenciada com uma Licença Creative Commons Atribuição 4.0 Internacional. 